\title{
Hipertansiyonlu Gebelerde Tuzdan Kısıtlı Diyete Uyum: Yarar ve Engel Algısı
}

\author{
Pınar AKYÜZ ${ }^{1}$, Neriman ZENGIN ${ }^{2}$
}

\begin{abstract}
$\ddot{\mathbf{O z}}$
$\mathrm{Bu}$ çalışma hipertansif gebelerin tuzdan kısıtlı diyete uyumda yarar ve engel algısını incelemek amacı ile yapıldı. Çalışmanın evrenini hipertansiyon nedeni ile gebe polikliniğine başvuran ve izlenen gebeler, örneklemini ise bu evrenden basit rastlantısal yöntemle seçilen 100 hipertansif gebe kadın oluşturdu. Veriler, gebelerin sosyodemografik ve obstetrik bilgilerini sorgulayan anket formu, tuz tüketimine yönelik tutum ve davranışları değerlendiren beş soru ve Diyete Uyum Ölçeği ile toplandı. Verilerin değerlendirilmesinde ortalama, standart sapma, median, frekans dağılımları, spearman korelasyon analizinden yararlanıldı ve anlamlılık 0,05 olarak kabul edildi. Yaş ortalamaları 31,16 olan gebelerin \%91'inde hipertansiyonun gebelikte ortaya çıktığı saptand. Gebelerin tuzdan kısıtlı diyete uyum durumları incelendiğinde Yarar Alt Boyut ortalama toplam puan1 28.73, Engel Alt Boyut ortalama toplam puan 12.65 olarak saptand1. Büyük çoğunluğu tuzdan kısitlı beslenmenin sağlık ve kalp üzerine olumlu etkilerini yarar algısı olarak, lezzet ve sosyal yaşamda kısıtlılıkları yol açmasının engel algısı olarak bildirdiği görüldü. Yarar algısının tuzdan kısıtlı beslenme ile ilgili tutum ve davranışları olumlu etkilediği saptandı. Gebelerin yarar ve engel algılarının iyi düzeyde olduğu görüldü. Ebeler düzenli izlemlerde gebelerin tuz tüketimi hakkındaki yarar ve engel algılarını, tutum ve davranışlarını değerlendirmelidir.
\end{abstract}

Yayın Bilgisi

Anahtar Kelimeler: Kan basıncı, gestasyonel hipertansiyon, diyet, az-tuzlu, düşük-sodyum, tuzsuz, ebelik, hemşirelik

\section{The Adherence of Pregnant Women with Hypertension to the Salt-Restricted Diet: Perceived}

\section{Benefits and Barriers}

Pınar AKYÜZ ${ }^{1}$, Neriman ZENGİN²

\begin{abstract}
The purpose of this study is to examine the perceived benefits and barriers, which are effective in adherence of pregnant women with hypertension to salt-restricted diet. The population of the study consisted of 100 pregnant women followed up due to hypertension in the gynecology outpatient clinic. The data were collected using the questionnaire inquiring the sociodemographic and obstetric information of the pregnant women; five questions assessing their attitudes and behaviors towards salt consumption; and the Dietary Compliance Scale. In evaluating of the data were used to mean, standard deviation, median, percentages and spearman correlation analysis. The pregnant women, whose average age was $31.16,91 \%$ of the pregnant women developed hypertension during their pregnancy. When the status of adherence to the salt restricted diet in pregnant women was examined, it was determined that while total score of the Benefit subscale was 28.73, total score of the Barrier subscale was 12.65.It was determined that the majority of the eating a low-salt diet reported positive effects on health and heart as a perceived benefit, and as a perceived barriers to causing limitations in taste and social life. attitudes and behaviors related to salt restricted diet were found to positively affect the perceived benefits. It was seen that the perceptions of benefits and barriers of pregnancies were at a good level. Midwives benefits of salt intake and regular follow-up of pregnant women in perceptions of barriers should evaluate their attitudes and behaviors.
\end{abstract}

Article Info

Gönderi Tarihi:06.02.2018

Kabul Tarihi:25.05.2018

Online Yayın Tarihi:30.06.2018

DOI: $10.26453 /$ otjhs.390557

Sorumlu Yazar

Neriman ZENGIN

Keywords: Blood pressure, high, gestational hypertension,, diet, low-salt, salt-free midwifery, nursing

\footnotetext{
${ }^{1}$ Sağlık Bilimleri Üniversitesi Ümraniye Eğitim ve Araştırma Hastanesi, İstanbul, Türkiye

${ }^{2}$ İstanbul Üniversitesi Sağlı Bilimleri Fakültesi, Ebelik Bölümü, İstanbul, Türkiye

* Çalışma İstanbul Üniversitesi Sağlık Bilimleri Enstitüsü Ebelik Anabilim Dalı Tezsiz Yüksek Lisans Programı Projesidir.
} 


\section{GíRIŞ}

Gebelikte görülen hipertansif sorunlar ve hipertansif sorunlarla ilişkili komplikasyonlar anne morbidite ve mortalitesinin en yaygin nedenlerinden biridir. $^{1-3}$ Amerika'da prevelans1 $\% 6,7-\% 8,3^{2}$, Türkiye'de yapılan çalışmalarda ise $\% 7,2^{4}$ ve $\% 7,6^{5}$ olarak bildirilmiştir. Gebelikte kronik, gestasyonel, kronik hipertansiyon üzerine eklenmiş preeklampsi ve eklampsi olmak üzere dört grupta incelenen ${ }^{6-8}$ hipertansif sorunların yönetiminde farmakolojik ve nonfarmakolojik tedavi yöntemlerinden yararlanılmaktadir. Nonfarmakolojik yaklaşımlar arasında düzenli egzersiz yapan kadınların gebelik sürecinde 1lımlı egzersize devam etmesi önerilirken kilo kaybı ve aşırı düşük sodyumlu (günde 100 mEq'den az) diyetler önerilmemektedir. ${ }^{3}$ Ayrıca klinik çalışmaların yetersizliği nedeniyle hipertansif gebe, gebeliğe bağlı hipertansiyon gelişen kadınlarda ya da sağlıklı gebelerde ne kadar tuz kısıtlaması yapılması gerektiğinin cevabı tam olarak verilememektedir. $\mathrm{Bu}$ nedenle gebe olmayan sağlıklı kişilerde olduğu gibi gebelerde de günlük tuz tüketiminin 5-6 g/gün olarak önerilmektedir. ${ }^{9}$

Aşırı tuz tüketiminden kaçınmanın yararlarının kabul edilmesine rağmen, insanlar bireysel ve çevresel nedenlerden dolayı diyetlerinde tuz miktarını azaltmakta zorlanmaktadır. ${ }^{10,11}$ Bireysel nedenler arasında aile yaşantısı, fiziksel özellikler ${ }^{11}$, tuzsuz gidaların lezzetsiz ve tatsız gelmesi, bireyin diyet uygulamaktan sıkılması, masada tuzluk kullanma alışkanlığı, kültürel beslenme alışkanlıkları ve bireylerin bu konuda bilgilerinin yetersiz olması yer almaktadır. ${ }^{10,12-22}$ Çevresel faktörler arasında ise tuzun yüzyıllardır geleneksel koruyucu olarak hem endüstriyel hem de ev içinde hazırlanan yemeklerde bakterilerin üremesini bağl1 bozulmaya engellemek ve lezzet vermek için kullanılması yer almaktadır. ${ }^{23}$ Hem bireysel hem de çevresel faktörler günlük tuz alım kaynakları olarak önemli role sahiptir.

Türkiye'de günlük tüketilen tuz miktar1 ${ }^{23,24}$ Dünya Sağlık Örgütünün önerdiği değerlerin ${ }^{25}$ çok üzerindedir. $\mathrm{Bu}$ durum dikkate alındığında hipertansif sorunları olan kadınların gebelik sürecinde ebe ve hemşireler tarafından tuz tüketimi yönünden beslenme özellikleri ile yarar ve engel algılarının değerlendirilmesi ve aşırı tuz tüketiminden kaçınma konusunda bilgilendirilmesinin önemi ortaya çıkmaktadır. Yarar algısı önerilen koruyucu davranışın bireyin kendinde oluşturacağı yarara inanması, engel algısı ise bireyin davranış1 gerçekleştirmede algıladığ yarar algısı hem de engel algısı sağlıklı davranışların güçlü belirleyicilerdir. ${ }^{28} \mathrm{Bu}$ tanımlayıcı çalışmanın birinci amacı hipertansif gebelerin tuz tüketimi hakkında tutumlarını, davranışlarını, yarar ve engel algılarını incelemek, ikinci amacı ise tutum davranış ile yarar ve engel algıları arasındaki ilişkiyi değerlendirmek olmak üzere iki amacı bulunmaktadır. 


\section{MATERYAL ve METOT}

\section{Araştırmanın Evren ve örneklemi}

Çalışmanın evrenini Mart -Temmuz 2016 tarihleri arasında hipertansiyon nedeni ile eğitim ve araştırma hastanesinin gebe polikliniğine başvuran ve izlenen gebeler, örneklemini ise bu evrenden basit rastlantısal yöntemle seçilen, çalışmaya katılmayı kabul eden, akut bir sağlık sorunu olmayan, Türkçe konuşan ve anlayan, 18 yaş ve üzeri 100 hipertansif gebe kadın oluşturdu.

\section{Veri Toplama Araçlart}

Veriler, gebelerin sosyodemografik, obstetrik ve hipertansiyonla ilgili durumlarını sorgulayan anket formu, literatür ${ }^{12,23,25,29-31}$ doğrultusunda yazarlar tarafindan hazırlanan tuz tüketimine yönelik tutum ve davranışları inceleyen beş ifadelik Tuz Tüketimine Karşı Tutum ve Davranış Soruları ve Diyete Uyum Ölçeği ${ }^{29}$ kullanılarak toplandı.

\section{Anket formu}

Sosyodemografik ve obstertik özelliklerden yaş, eğitim durumu, kronik hastalık olma durumu, sigara içme durumu, gebelik haftası ve gebelik sayıs1 sorguland1. Hipertansiyonla ilgili özelliklerden; hipertansiyonun gebelik sürecinde ortaya çıkma durumu, kontrolle gelme sıklığı, kan basıncinı takip etme durumu, kan basıncında yükselme sıklığı, diyet uygulama durumu, ödem derecesi, kan ve idrar sodyum değeri, tuz kısıtlamasına dikkat etme durumunu sorgulayan soruları yer ald1. Gebelerin ödem derecesi tibia kemiği üzerine iki parmakla kuvvetlice 2-3 saniye süre ile basınç uygulaması ve oluşan godenin geri dönme hızı ile belirlendi. Godenin 15 sn'de geri dönmesi bir pozitif, 1530 sn'de geri dönmesi iki pozitif, 30-45 sn'de geri dönmesi üç pozitif, 45 sn'den daha uzun sürede geri dönmesi dört pozitif ödem olarak kabul edildi. ${ }^{32}$

\section{Tuz Tüketimine Karşı Tutum ve Davranış}

Diyette tuz tüketimini azaltmaya yönelik tutum ve davranışlar literatür doğrultusunda ${ }^{12,23,25,29-31}$ yazarlar tarafindan hazırlanan ifadelerle değerlendirilmiştir. Bu ifadeler; tuzsuz ya da az tuzlu diyetten memnun olma, az tuzlu beslenmeyi sürdürmede kararlılık, yemek masasinda tuzluk kullanma, sosyal ortamda tuz tüketimine dikkat etme, hazır gidaların etiketlerini içerdiği tuz miktarı yönünden kontrol etmedir. İfadelerin 1 (kesinlikle katılmiyorum) -5 (kesinlikle katıliyorum) arasında likert tipi derecelendirildiği sorularda toplam puanı 5-35 arasında değişmekte olup; yüksek puan olumlu tutum ve davranış1 göstermektedir. Çalışmada bu formun Cronbach alfa katsayısı 0,57 olarak saptandı.

\section{Diyete Uyum Ölçeği (BDCS)}

Bennett ve ark. $(1997)^{29}$ tarafindan tuz kısıtlamasına uyumda yarar ve engel algılarını değerlendirmek için geliştirilmiştir. Beşli likert $(1=$ Kesinlikle katılmiyorum, $5=$ Kesinlikle katılıyorum) ölçek 12 ifade ile yarar ve engel olmak üzere iki alt boyuttan oluşmaktadır. Yarar alt boyut toplam puanı 7-35 ve orta nokta puanı 
21 olup; diyette bireyin tuz kısıtlaması ile ilgili yarar algılarını değerlendirmektedir. Engel alt boyut toplam puanı 5-25, orta nokta puanı 15 olup, bireyin tuz kısitlamasina uyumuna engel olarak algıladığı durumları değerlendirmektedir. Ölçekte toplam puan alınmamakta ve her iki alt boyut ayrı olarak değerlendirilmektedir. Yüksek puan yarar ve engel algısının yükssek olduğunu göstermektedir. ${ }^{33}$ Yapılan çalışmalarda Cronbach alfha katsayısı yarar alt boyutu için 0.67-0.88, engel alt boyutu için 0.66-0.77 arasında değiştiği görülmüştür. ${ }^{33,34}$ Ölçek Oğuz ve arkadaşları tarafından 2010 yılında Türkçeye uyarlanmış ve Cronbach alfa katsayısı yarar alt boyut için 0.71 engel alt boyut için 0.58 olarak saptanmıştır. $^{35}$ Mevcut çalışmada ölçeğin Cronbach alfa katsayıları yarar alt boyut için 0.87 , engel alt boyut için 0.76 olarak belirlendi.

\section{Verilerin toplanmast}

Araştırma öncesi gebelere çalışma hakkında bilgi verilmiş ve onam alınmıştır. Çalışmanın verileri çalışmaya dahil olma kriterlerine uyan ve çalışmaya katılmayı kabul eden gebelerden araştırmacılar, poliklinikte görevli ebeler, hemşireler tarafından yüz yüze görüşme yöntemi ile toplanmıştır.

\section{Araştırmanın Etik Yönü}

Çalışmaya başlamadan önce çalışmanın yürütüleceği hastaneden, etik komiteden izin alınmış ve çalışmaya katılmayı kabul eden hipertansif gebeler örnekleme dahil edilmiştir.

\section{Verilerin Değerlendirilmesi}

Çalışmada elde edilen verilerin 0.05 anlamlılık düzeyinde SSPS 21 istatistik programından tanımlayıcı istatistiksel yöntemler (ortalama, standart sapma, median, yüzde) ve spearman korelasyon analizi ile değerlendirilmiştir.

\section{BULGULAR}

Yaş ortalamaları 31.16 olan gebelerin $\% 51^{\prime} i$ orta öğrenim mezunu, \%59'u çalışmamaktadır. Ortalama gebelik haftası $36.11 \pm 3.09$ olan gebelerin \%12'si sigara içmekte ve \%12'sinin kronik bir hastalığı bulunmaktadır. Gebelerin \%90'nı isteyerek gebe kaldıklarını belirtmiştir (Tablo 1).

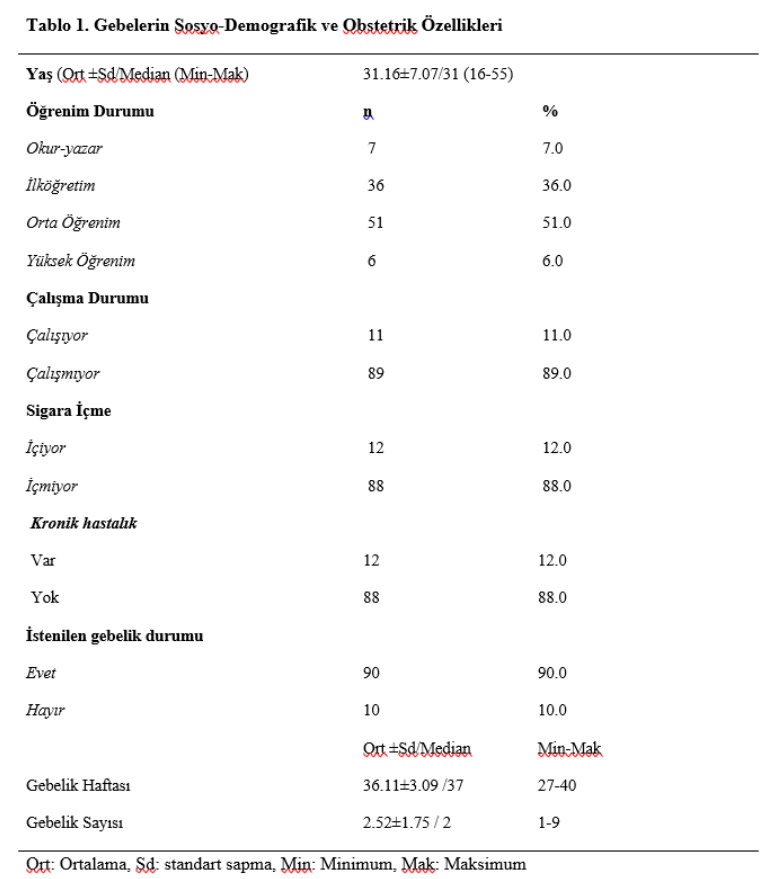

Gebelerin \%91'inde hipertansiyonun gebelikte ortaya çıktığı, \%52'sinin her hafta kontrolle geldiği, \%36'sında kan basıncının haftada bir iki kez yüksseldiği, \%45'inin günde birkaç kez kan basıncını ölçtügü ve \%43'ünde iki pozitif ödemi olduğu saptandı (Tablo 2). 


\begin{tabular}{|c|c|c|}
\hline Gebelikle birlikte kan basincinda yükselme & 2 & $\%$ \\
\hline Evet & 91 & 90.0 \\
\hline Hayir & 9 & 10.0 \\
\hline \multicolumn{3}{|l|}{ Kontrolle gelme siklı̆̆ } \\
\hline Her hafta & 52 & 52.0 \\
\hline Ayda bir & 28 & 28.0 \\
\hline Sikayetio olduğunda & 20 & 20.0 \\
\hline \multicolumn{3}{|l|}{ Kan basnca takibi yapma durumu } \\
\hline Günde birkaç kez & 45 & 45.0 \\
\hline Günde bir kez & 24 & 24.0 \\
\hline Haftada $1-2 \mathrm{kez}$ & 17 & 17.0 \\
\hline Haftada $1 \mathrm{kez}$ & 6 & 6.0 \\
\hline Ayda birkaç kez & 8 & 8.0 \\
\hline \multicolumn{3}{|l|}{ Kan basuncinda yükselme siklă } \\
\hline Her gün & 16 & 16.0 \\
\hline Haftada iki üç kez & 36 & 36.0 \\
\hline Haftada bir kez & 30 & 30.0 \\
\hline Ayda iki üç kez & 15 & 15.0 \\
\hline Ayda bir kez & 3 & 3.0 \\
\hline \multicolumn{3}{|l|}{ Diyet uygulama durumu } \\
\hline Evet & 87 & 87.0 \\
\hline Hayir & 13 & 13.0 \\
\hline \multicolumn{3}{|l|}{ Ödem derecesi } \\
\hline $1+$ & 36 & 36.0 \\
\hline $2++$ & 43 & 43.0 \\
\hline $3+++$ & 21 & 21.0 \\
\hline
\end{tabular}

Gebelerin tuzdan kısitlı diyete yarar alt boyut toplam ortalama puanı $28.73 \pm 4.42$ olup büyük çoğunluğunun tuzdan kısıtlı diyete yarar algısı olarak "Az tuzlu diyetle beslenmek sağlıklı olmamı sağlayacak (4.28 \pm 0.79$)$ ", “Tuzlu yiyecekler benim için iyi değildir (4.16 \pm 0.89$)$ " ve "Az tuzlu yiyecekle beslenme kalp sağlığımı koruyacaktır (4.21 \pm 0.67$)$ " ifadelerine katıldığ saptand1 (Tablo 3). Gebelerin Engel Alt Boyut toplam puanın 12.65 \pm 3.04 olup; "büyük çoğunluğunun tuzdan kısıtlı diyete engel algısı olarak "Tuzu az olan yiyecekler lezzetsiz geliyor (3.06 \pm 1.07$)$ ", “Az tuzlu diyetle beslenmek lokantaya gitmemi zorlaştırmaktadır $(2.85 \pm 1.16) "$ ifadelerine katıldığı görüldü (Tablo 3).

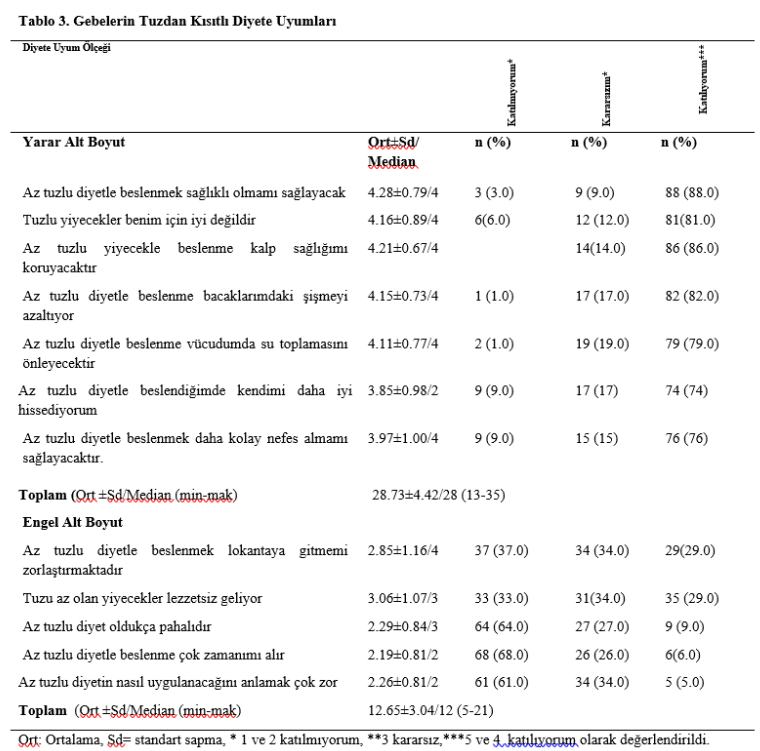

Hipertansif gebelerin tuz tüketimine karşı tutum ve davranışları incelendiğinde \%62'sinin diyetindeki tuz oranından memnun olmadığ 1 , \%45'inin tuzsuz beslenmeyi sürdürmede kararlı olduğu, \%51'nin yemek masasında tuzluk kullanmadığını， \%43'ünün sosyal ortamda yiyeceklerdeki tuz oranına dikkat ettiği ve \%56'sının hazır gidaların etiketlerini kontrol ettiğini bildirmiştir (Tablo 4). Hipertansif gebelerin diyetlerinde tuz kısıtlaması ile ilgili Yarar ve Engel Alt Boyut toplam puanları ile tuz kısıtlamasına yönelik tutum ve davranış sorularının toplam puanı arasındaki ilişki incelendiğinde Yarar Alt Boyut ile düşük düzeyinde pozitif anlamlı ilişki $(r=0.252$, $\mathrm{p}<0.05)$ saptanırken, Engel Alt Boyut ile anlamlı ilişki saptanmamıştır (Tablo 4). Hipertansif bireylerin tuzdan kisitlı beslenme ile ilgili yarar algiları artarken, tuzdan kısıtlı beslenmeye karşı olumlu tutum ve davranış göstermektedirler. Ancak engel algıları ile tutum ve davranışları arasında ilişki görülmedi. 
Tablo 4. Hipertansif Gebelerin Tuz Tüketimine Karșı Tutum ve Davranıșları ve Diyete uyum ölçeği ile iliṣkisi

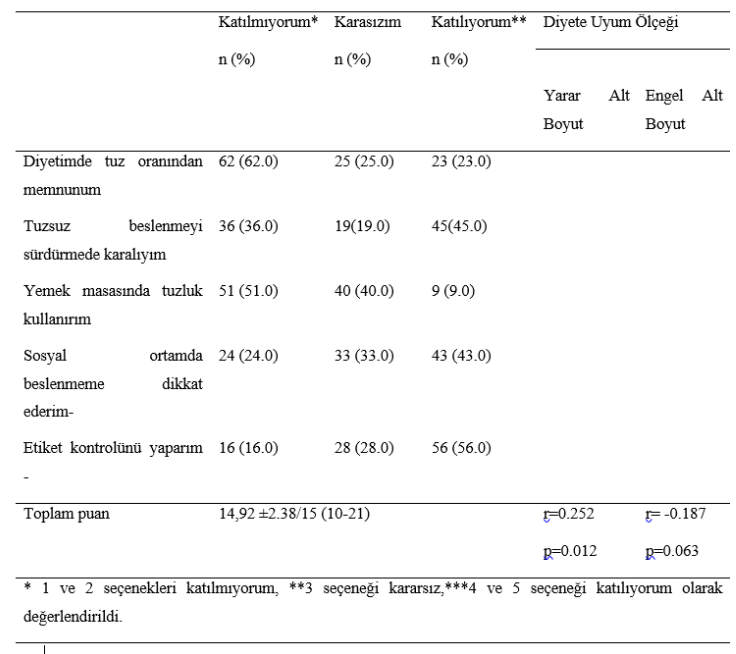

\section{TARTIŞMA}

Gebe olmasına bakılmaksızın hipertansiyonu olan ve olmayan tüm bireylere günlük tuz alımının $5 \mathrm{~g}$ ve altında olması önerilen önemli bir yaşam biçimi değişikliğidir. Ülkemizde 2008 yılında yapılan çalışmada günlük tuz tüketimi $18 \mathrm{~g} /$ gün, ${ }^{24} 2012$ yapılan çalışmada ise 15 g/gün. ${ }^{23}$ olarak belirlenmiştir. Bu oran Dünya Sağlık Örgütünün önerdiği günlük tuz tüketim miktarından (5-6 g/gün) oldukça fazladır. ${ }^{25} \mathrm{Bu}$ nedenle bireysel ve çevresel faktörler göz önüne alınarak davranış değişikliği sağlanması, günlük alınan tuz miktarının azaltılmasında önemli role sahip olacaktır. Davranış değişikliğinde ise yarar ve engel algısı en önemli sağlık inançlarından biridir.

Hemodiyaliz hastalarında tuzdan kısıtlı diyete uyumu inceleyen Wechl ve ark. $(2006)^{36}$ ve Walsh ve ark. $(2011)^{18}$ çalışmalarında, Bennet ve ark. $(2005)^{33}$ kalp yetmezliği hastalarında ortalama yarar alg1s1 puanı orta noktanın üzerinde, ortalama engel alg1s1 puanı ise orta noktanın altında olduğu bildirilmiştir. Mevcut çalışmada ise hipertansif gebelerin ortalama yarar alg1sı puanı 28.73 engel algısı puanı 12.65 olarak saptanmıştır. Yarar algısında ortalama puan orta noktanın üzerinde (21), engel algısında ise orta noktanın (15) altında olduğu görülmüştür (Tablo 1). Her üç çalışmanın sonuçlar1 ${ }^{18,22}$ hastalık grubu ve kültürel olarak farklı toplumlarda yapılmış olmakla birlikte, mevcut çalışma sonuçları ile benzerlik göstermektedir. Ayrıca hipertansif gebelerin yarar ve engel algısı, kalp yetmezliği ${ }^{33}$ ve diyaliz hastalarının ${ }^{18,34}$ yarar ve engel algısından oldukça iyi olduğu görüldü. $\mathrm{Bu}$ sonuçta gebelerin bebeğin sağlığı ile ilgili endişelerinin de etkili olduğu düşünülebilir. Gebelerde yapılan bir çalışmada optimal beslenmede algılanan yararın bebek sağlığı üzerindeki olumlu etkileri ile ilişkili olduğu görülmüştür. ${ }^{30}$ Ayrıca yapılan çalışmalarda gebelerin sağlıklı yaşam biçimi davranışlarının iyi düzeyde olduğu bildirilmektedir. ${ }^{37}$

Hemodiyaliz hastalarında yapılan çalışmalarda, tuz kısıtlamasına uyumda hastaların çoğu yarar alg1sı olarak "tuzlu yiyeceklerin kendileri için iyi olmamasını, az tuzlu yiyecekle beslenmenin kalp sağlığını koruyacağını"18,22 bildirmektedir. Yapılan başka bir çalışmada ise çoğunlukla, sağlıklı bir diyetin yararları olarak sağlıklı olma / hastalıkları önleme, kilo kontrolü, iyi olma ve yaşam kalitesi olarak belirtilmiştir. ${ }^{38}$ Mevcut çalışmada hipertansif gebeler tuzdan kısıtlı diyete uyumda en çok yarar algısı olarak "az 
tuzlu diyetle beslenmenin kalp sağlı̆̆ını koruması" ve "tuzlu yiyeceklerin kendileri için iyi olmamasını" bildirmiştir (Tablo 1). Hem mevcut çalışmada hem de yapılan çalışmalarda ${ }^{18,36,38}$ çoğunlukla yarar algısı olarak tuzdan kısıtlı beslenmenin sağlık ve kalp üzerine olumlu etkileri ilk siralarda yer almaktadır.

Hipertansif hastalarda tuz kisitlamasina engel olan faktörler arasında yiyeceklerin lezzetsiz gelmesi, aynı şeyleri yemekten sıkılma $a^{18-20,36}$ ve bilgi eksikliğ ${ }^{39}$ olduğu bildirilmektedir. Holgado et al. $(2000)^{38}$ çalışmasında sağlıklı diyeti sürdürmeyi engelleyen faktörleri düzensiz çalışma saatleri, sevilen yiyeceklerden vazgeçememe, irade eksikliği, yoğun yaşam tarzı, yiyecek fiyatları, yemek hazırlama sorunları, lezzetsiz yiyecekler, bilgi eksikliği olarak belirtilmektedir. Mevcut çalışmada ise hipertansif gebeler, tuzdan kisitlı diyete uyumlarını engelleyen başlıca faktörler olarak lezzet ve diyetin sosyal yaşamda kısıtlılıklara neden olmasını belirtmiştir ve bu bulgular literatürle ${ }^{12,18-20,22,29,40}$ benzerlik göstermektedir.

Khoramabadi ve ark. (2016) randomize kontrollü çalışmasında gebelere verilen beslenme eğitiminin algılanan yarar ve engel algısını olumlu yönde etkilediğini, diyet davranışları ile yarar algısı arasında zayıf düzeyde anlamlı ilişki bulunduğunu bildirirken, engel algısı ile ise ilişki bulunmadığını bildirmiştir. $^{30}$ Mevcut çalışmada da benzer sonuçlar görülmüştür. Hipertansif gebelerin yarar algısı artarken diyette tuz tüketimini azaltmaya yönelik tutum ve davranışları olumlu yönde etkilenmektedir (Tablo 4). $\mathrm{Bu}$ sonuç sağlık inancı ile davranış arasındaki ilişkinin bir göstergesi olarak düșündürebilir. ${ }^{26}$

\section{SONUÇ VE ÖNERİLER}

$\mathrm{Bu}$ çalışmanın sonucunda hipertansif gebelerin;

- tuzdan kısitlı beslenmeye yönelik yarar ve engel algısının iyi düzeyde olduğu,

- büyük çoğunluğunun yarar algısı olarak tuzdan kısıtlı beslenmenin sağlık ve kalp üzerine olumlu etkilerini, engel algısı olarak lezzet ve diyetin sosyal yaşamda kısıtlılıklara neden olmasını bildirdiği,

- \%62'sinin diyetindeki tuz oranından memnun olmadığı, \%51'nin yemek masasında tuzluk kullanmadığı, \%43'ünün sosyal ortamda yemeklerde tuz oranına dikkat ettiği ve \%56'sının hazır gidaların etiketlerini kontrol ettiği,

- tuzdan kisitlı beslenmenin yararına olan inançları artarken, olumlu tutum ve davranışlar gösterdiği saptanmıştır.

Koruyucu sağlık hizmetlerinde önemli rolü olan ebeler gebelerin sağlıklı bir gebelik, doğum, doğum sonu dönem geçirmeleri için düzenli aralıklarla gebeleri izlemelidir. $\mathrm{Bu}$ dönemde hipertansiyon ve ödem saptanan gebelerin özellikle aşırı tuz tüketimi açısından beslenme alışkanlıklarını değerlendirmelidir. Ebeler tuz tüketimi konusunda yarar ve engel algılarını, 
tutum ve davranışları belirledikten sonra beslenme eğitimini planlamalıdır.

\section{KAYNAKLAR}

1. Global Health Observatory (GHO) Data. Maternal and Reproductive Health. 2018; http://www.who.int/gho/maternal_health/en/ Accessed 03-02-2018, 2018.

2. Kuklina EV, Ayala C, Callaghan WM. Hypertensive disorders and severe obstetric morbidity in the United States. Obstet Gynecol. 2009;113(6):1299-1306.

3. Moussa HN, Arian SE, Sibai BM. Management of hypertensive disorders in pregnancy. Women's Health. 2014;10(4):385-404.

4. Ersoy H, Sari O, Aydogan U, et al. Hypertension prevalance in pregnant women refered to the gynecology and obstetrics clinic of a faculty of medicine. Turkish Nephrology Dialysis Transplantation. 2011;20(02):187-191.

5. Çulha G, Ocaktan ME, Çöl M. Ankara Üniversitesi Tıp Fakültesi kadın hastalıkları ve doğum polikliniğine başvuran gebelerde hipertansiyon araştırması. Turkiye Klinikleri Journal of Medical Sciences. 2010;30(2):639-649.

6. Townsend R, O'Brien P, Khalil A. Current best practice in the management of hypertensive disorders in pregnancy. Integr Blood Press Control. 2016;9:79-94.

7. Berhan Y, Endeshaw G. Maternal mortality predictors in women with hypertensive disorders of pregnancy: a retrospective cohort study. Ethiop J Health Sci. 2015;25(1):89-98.

8. Özkayar N. Gebelikte hipertansiyon ve tedavisi. Turkiye Klinikleri Journal of Nephrology Special Topics. 2017;10(1):6368.

9. Özkan G. Hangi hastaya ne kadar tuz kısitlaması yapılmalı? Hipertansiyon Haber Bülteni 2016;3(5):7-9.

10. Ohta Y, Ohta K, Ishizuka A, et al. Awareness of salt restriction and actual salt intake in hypertensive patients at a hypertension clinic and general clinic. Clin Exp Hypertens. 2015;37(2):172-175.

11. Ohta Y, Kimura Y, Kitaoka C, Sakata T, Abe I, Kawano Y. Blood pressure control status and relationship between salt intake and lifestyle including diet in hypertensive outpatients treated at a general hospital. Clin Exp Hypertens. 2017;39(1):29-33.

12. Bentley B, De Jong MJ, Moser DK, Peden AR. Factors related to nonadherence to low sodium diet recommendations in heart failure patients. Eur J Cardiovasc Nurs. 2005;4(4):331-336.

13. Sheahan SL, Fields B. Sodium dietary restriction, knowledge, beliefs, and decisionmaking behavior of older females. J Am Acad Nurse Pract. 2008;20(4):217-224.

14. Kim MJ, Ahn YH, Chon C, Bowen P, Khan S. Health disparities in lifestyle choices among hypertensive Korean Americans, non- 
Hispanic Whites, and Blacks. Biol Res Nurs. 2005;7(1):67-74.

15. De Keyzer W, Tilleman K, Ampe J, De Henauw S, Huybrechts I. Effect of sodium restriction on blood pressure of unstable or uncontrolled hypertensive patients in primary care. Nutr Res Pract. 2015;9(2):180-185.

16. Young L, Barnason S. Uptake of dietary sodium restriction by overweight and obese patients after cardiac revascularization. Rehabil Nurs. 2016;41(3):149-57.

17. Kollipara UK, Jaffer O, Amin A, et al. Relation of lack of knowledge about dietary sodium to hospital readmission in patients with heart failure. Am J Cardiol. 2008; 102(9): 1212-1215.

18. Walsh E, Lehane E. An exploration of the relationship between adherence with dietary sodium restrictions and health beliefs regarding these restrictions in Irish patients receiving haemodialysis for end-stage renal disease. Journal of clinical nursing. 2011;20(3-4):331-340.

19. McMahon EJ, Campbell KL, Mudge DW, Bauer JD. Achieving salt restriction in chronic kidney disease. International journal of nephrology. 2012;2012:720429.

20. Park KA, Choi-Kwon S, Sim YM, Kim SB. Comparison of dietary compliance and dietary knowledge between older and younger Korean hemodialysis patients. J Ren Nutr. 2008;18(5):415-423.
21. Kastarinen MJ, Puska PM, Korhonen MH, et al. Non-pharmacological treatment of hypertension in primary health care: a 2-year open randomized controlled trial of lifestyle intervention against hypertension in eastern Finland. J Hypertens. 2002; 20(12): 25052512.

22. Welch JL, Astroth KS, Perkins SM, et al. Using a mobile application to self-monitor diet and fluid intake among adults receiving hemodialysis. Res Nurs Health. 2013; 36(3): 284-298.

23. Türkiye Aşırı Tuz Tüketiminin Azaltılması Program1 2017-2021. 2. Basım ed. Ankara: Sağlık Bakanlığı,Türkiye Halk Sağlığ1 Kurumu Obezite, Diyabet ve Metabolik Hastalıklar Daire Başkanlığg 2016.

24. Erdem Y, Arici M, Altun B, et al. The relationship between hypertension and salt intake in Turkish population: SALTURK study. Blood Press. 2010;19(5):313-318.

25. Sodium intake for adults and children. Geneva, Switzerland: World Health Organization; 2012.

26. Çenesiz E, Atak N. Türkiye'de sağlık inanç modeli ile yapılmış araştırmaların değerlendirilmesi. TSK Koruyucu Hekimlik Bülteni. 2007;6(6):427-434.

27. Gözüm S, Çapık C. Sağlık Davranışlarının Geliştirilmesinde Bir Rehber: Sağlık İnanç Modeli. DEUHYO ED 2014;7(3): 230-237

28. Carpenter CJ. A meta-analysis of the effectiveness of health belief model variables 
in predicting behavior. Health Commun. 2010;25(8):661-669.

29. Bennett SJ, Milgrom LB, Champion V, Huster GA. Beliefs about medication and dietary compliance in people with heart failure: an instrument development study. Heart Lung. 1997;26(4):273-279.

30. Khoramabadi M, Dolatian M, Hajian S, et al. Effects of Education Based on Health Belief Model on Dietary Behaviors of Iranian Pregnant Women. Glob J Health Sci. 2015;8(2):230-239.

31. O'Shaughnessy KM. Role of diet in hypertension management. Curr Hypertens Rep. 2006;8(4):292-297.

32. Enç N, Uysal H, Öz Alkan H. Üriner sistemin Tanılanması ve Fiziksel Muaynesi. In: Enç N, ed. Sağlık Tanılaması ve Fiziksel Muayene. İstanbul: Nobel Tip Kitapevi; 2012:90-103.

33. Bennett SJ, Lane KA, Welch J, Perkins SM, Brater DC, Murray MD. Medication and dietary compliance beliefs in heart failure. West J Nurs Res. 2005;27(8):977-993.

34. Welch JL, Bennett SJ, Delp RL, Agarwal R. Benefits of and barriers to dietary sodium adherence. West J Nurs Res. 2006;28(2):162180.
35. Oğuz S, Enç N, Yiğit Z. Kronik kalp yetersizliği olan hastalar için inanç ve uyum ölçeklerinin Türkçeye uyarlanması. Türk Kardiyol Dern Arş. 2010;38:480-485.

36. Welch JL, Astroth KS, Perkins SM, et al. Using a mobile application to self-monitor diet and fluid intake among adults receiving hemodialysis. Res Nurs Health. 2013;36(3):284-298.

37. Onat G, Aba YA. Health-promoting lifestyles and related factors among pregnant women. Turkish Journal of Public Health. 2014;12(2):69.

38. Holgado B, de Irala-Estevez J, MartinezGonzalez MA, Gibney M, Kearney J, Martinez JA. Barriers and benefits of a healthy diet in spain: comparison with other European member states. Eur J Clin Nutr. 2000;54(6):453-459.

39. Elmas A, Aral E, Tuğrul A, Şengül E, Bülbül F. Hemodializ hastalarında beslenme bilgi düzeyi ile klinik ve laboratuar bulguları arasındaki ilişki. Kocaeli Tıp Dergisi. 2012;3:23-26.

40. Kurt Y EE, Kaya C ve ark. . Hemodiyaliz hastalarına verilen eğitimin kan basıncı ve kilo alımına etkisi. Turk Nephrol Dial Transplant. 2012;21(1):39-44. 
Tablo 1. Gebelerin Sosyo-Demografik ve Obstetrik Özellikleri

Yaş $(\mathrm{Ort} \pm \mathrm{Sd} /$ Median (Min-Mak)

Öğrenim Durumu

Okur-yazar

Ilkögretim

Orta Ögrenim

Yüksek Öğrenim

\section{Çalışma Durumu}

Çalışıyor

Çalışmıyor

Sigara İçme

İçiyor

İçmiyor

Kronik hastallk

Var

Yok

İstenilen gebelik durumu

Evet

Hayır

Gebelik Haftas1

Gebelik Sayısı
$31.16 \pm 7.07 / 31(16-55)$

n

$\%$

7

7.0

36

36.0

51

51.0

6

6.0

11.0

89

89.0

12

88

88.0

88

88.0

$90-90.0$

$10 \quad 10.0$

Ort $\pm \mathrm{Sd} /$ Median $\quad$ Min-Mak

$36.11 \pm 3.09 / 37 \quad 27-40$

$2.52 \pm 1.75 / 2 \quad 1-9$

Ort: Ortalama, Sd: standart sapma, Min: Minimum, Mak: Maksimum 
Tablo 2. Gebelerin Hipertansiyon ile ilgili özellikleri

Gebelikle birlikte kan basıncında yükselme

Evet

Hayır

Kontrolle gelme sıklı̆̆

Her hafta

Ayda bir

Şikayeti olduğunda

Kan basıncı takibi yapma durumu

Günde birkaç kez

Günde bir kez

Haftada 1-2 kez

Haftada $1 \mathrm{kez}$

Ayda birkaç kez

Kan basıncında yükselme sıklığı

Her gün

Haftada iki üç kez

Haftada bir kez

Ayda iki üç kez

Ayda bir kez

\section{Diyet uygulama durumu}

Evet

Hayır

\section{Ödem derecesi}

$1+$

$2++$

$3+++$ 
Tablo 3. Gebelerin Tuzdan Kısıtlı Diyete Uyumları

\section{Diyete Uyum Ölçeği}

\section{Yarar Alt Boyut}

Az tuzlu diyetle beslenmek sağlıklı olmamı sağlayacak

Tuzlu yiyecekler benim için iyi değildir

$\mathrm{Az}$ tuzlu yiyecekle beslenme kalp sağlığımı koruyacaktır

Az tuzlu diyetle beslenme bacaklarımdaki şişmeyi azaltiyor

Az tuzlu diyetle beslenme vücudumda su toplamasinı önleyecektir

Az tuzlu diyetle beslendiğimde kendimi daha iyi hissediyorum

Az tuzlu diyetle beslenmek daha kolay nefes almamı sağlayacaktır.

Toplam (Ort $\pm \mathrm{Sd} /$ Median (min-mak)

\section{Engel Alt Boyut}

$\mathrm{Az}$ tuzlu diyetle beslenmek lokantaya gitmemi zorlaştırmaktadır

Tuzu az olan yiyecekler lezzetsiz geliyor

Az tuzlu diyet oldukça pahalıdır

Az tuzlu diyetle beslenme çok zamanımı alır

Az tuzlu diyetin nasıl uygulanacağını anlamak çok zor

Toplam (Ort $\pm \mathrm{Sd} /$ Median (min-mak)
$2.85 \pm 1.16 / 4 \quad 37(37.0) \quad 34(34.0) \quad 29(29.0)$

$3.06 \pm 1.07 / 3 \quad 33(33.0) \quad 31(34.0) \quad 35(29.0)$

$2.29 \pm 0.84 / 3 \quad 64(64.0) \quad 27(27.0) \quad 9(9.0)$

$2.19 \pm 0.81 / 2 \quad 68(68.0) \quad 26(26.0) \quad 6(6.0)$

$2.26 \pm 0.81 / 2 \quad 61(61.0) \quad 34(34.0) \quad 5(5.0)$

$12.65 \pm 3.04 / 12(5-21)$

Ort: Ortalama, $\mathrm{Sd}=$ standart sapma, $* 1$ ve 2 katılmıyorum, $* * 3$ kararsı, $* * * 5$ ve 4 katılıyorum olarak değerlendirildi. 
Tablo 4. Hipertansif Gebelerin Tuz Tüketimine Karşı Tutum ve Davranışları ve Diyete uyum ölçeği ile ilişkisi

\begin{tabular}{ccccc} 
Katılmıyorum* & Karasızım & Katılıyorum** & Diyete Uyum Ölçeği \\
\cline { 4 - 5 } $\mathrm{n}(\%)$ & $\mathrm{n}(\%)$ & $\mathrm{n}(\%)$ & & \\
& & & Yarar Alt & Engel Alt \\
& & & Boyut & Boyut
\end{tabular}

\begin{tabular}{|c|c|c|c|c|c|}
\hline $\begin{array}{l}\text { Diyetimde tuz oranından } \\
\text { memnunum }\end{array}$ & $62(62.0)$ & $25(25.0)$ & $23(23.0)$ & & \\
\hline $\begin{array}{l}\text { Tuzsuz beslenmeyi } \\
\text { sürdürmede karalıyım }\end{array}$ & $36(36.0)$ & $19(19.0)$ & $45(45.0)$ & & \\
\hline $\begin{array}{l}\text { Yemek masasında tuzluk } \\
\text { kullanırım }\end{array}$ & $51(51.0)$ & $40(40.0)$ & $9(9.0)$ & & \\
\hline $\begin{array}{l}\text { Sosyal ortamda } \\
\text { beslenmeme dikkat } \\
\text { ederim- }\end{array}$ & $24(24.0)$ & $33(33.0)$ & $43(43.0)$ & & \\
\hline Etiket kontrolünü yaparım & $16(16.0)$ & $28(28.0)$ & $56(56.0)$ & & \\
\hline Toplam puan & & $\pm 2.38 / 15$ & & $\begin{array}{l}\mathrm{r}=0.252 \\
\mathrm{p}=0.012\end{array}$ & $\begin{array}{l}\mathrm{r}=-0.187 \\
\mathrm{p}=0.063\end{array}$ \\
\hline
\end{tabular}

